\title{
Carl Schmitt, lector de Georges Sorel. La crítica al parlamentarismo, el mito de la nación y la «mirada rusa».
}

\author{
Carl Schmitt, reader of Georges Sorel. The Critique of Parliamentarianism, \\ the Myth of the Nation and the "Russian look".
}

\author{
Por: Aguirre, German Rodrigo * \\ UBA, FSOC, IIGG, CONICET \\ Buenos Aires, Argentina. \\ Email: aguirregermanr@gmail.com
}

Fecha de recepción: 04/09/2020

Fecha de aprobación: 16/10/2020

DOI: http://dx.doi.org/10.30972/nvt.1624495

\section{Resumen}

El presente artículo pretende desplegar la recuperación schmittiana del pensamiento de Georges Sorel. Para ello, la exposición se divide en dos momentos. En primer lugar, realizaremos una lectura cercana de Los fundamentos históricoespirituales del parlamentarismo en su situación actual (1923), obra de Schmitt en la cual la figura de Sorel adquiere un explícito protagonismo. A partir de dicha restitución, planteamos que Sorel constituye un corolario que da cuenta de manera más acabada tanto de la crítica schmittiana al parlamentarismo como del antagonismo con la Revolución Rusa. En segundo lugar, intentamos mostrar la perduración de tópicos sorelianos deteniéndonos en la conferencia «La era de las neutralizaciones y de las despolitizaciones» (1929). Allí, veremos que la problemática teórico-política abierta en 1923 continúa bajo la forma de un enfrentamiento vital y se corresponde con las primeras enunciaciones schmittianas acerca de la politización total y el Estado total.

\footnotetext{
* Licenciado en Ciencia Política por la Universidad de Buenos Aires (UBA). Becario doctoral del CONICET con sede en el Instituto de Investigaciones Gino Germani de la UBA. Docente de grado en teoría política.
} 
Carl Schmitt, lector de Georges Sorel.

La crítica al parlamentarismo, el mito de la nación y la «mirada rusa»

Palabras clave: Carl Schmitt, Georges Sorel, Mito, Politización, Neutralización, Parlamentarismo.

\section{Abstract}

This article aims to analyse the Schmittian interpretation of Georges Sorel's thought. To this end, the work is divided into two moments. In the first place, we will make a close reading of The Intellectual-Historical Situation of Today's Parliamentarianism (1923), a work by Schmitt in which the figure of Sorel takes on an explicit prominence. From this restitution, we propose that Sorel constitutes a corollary that gives a more complete account of both Schmitt's criticism of parliamentarianism and the author's antagonism with the Russian Revolution. Secondly, we try to show the persistence of Sorelian topics by focusing on the conference "The Age of Neutralization and Depoliticization" (1929). There, we will see that the theoretical-political problem opened in 1923 continues in the form of a vital confrontation and corresponds to the earliest Schmittian enunciations about total politicization and the total state.

Keywords: Carl Schmitt, George Sorel, Myth, Politization, Neutralization, Parliamentarianism.

\section{Cómo citar este artículo:}

APA: Aguirre, G. R. (2020). Carl Schmitt, lector de Georges Sorel. La crítica al parlamentarismo, el mito de la nación y la «mirada rusa». Nuevo Itinerario, 16 (2), 1-26. Recuperado de: (agregar dirección web)

\section{Introducción}

Que un intelectual anarcosindicalista francés como Georges Sorel (1847-1922) se encuentre presente en el pensamiento de un jurista conservador $y$ antirrevolucionario como Carl Schmitt (1888-1985) seguramente sea sorprendente 
para muchos. Basta recordar los vehementes párrafos finales de Teología política (1922) y Catolicismo romano y forma política (1923), en los cuales el enemigo anarquista es encarnado en la figura de Mijaíl Bakunin, para apreciar la distancia de Schmitt respecto del pensador francés (Schmitt, 2001, 2009).

Lo cierto es que la mención a Sorel aparece en las principales obras de la década de 1920 del Jurist. Ya en La dictadura (1921), el nombre de Sorel es señalado en relación a la filosofía de la historia y la dictadura del proletariado (Schmitt, 1968). En Teología política el autor francés es ubicado dentro de una filosofía irracionalista que aúna el vitalismo de Henri Bergson con el economicismo marxista (Schmitt, 2001, p. 47). En Catolicismo romano y forma política Schmitt identifica a Sorel como parte del bando del pensamiento económico -integrado tanto por el liberalismo como por el marxismo-, el cual lucha contra lo político (Schmitt, 2009, p. 60). Hasta aquí, no obstante, no deja de haber meras menciones ocasionales ${ }^{1}$.

En 1923 Schmitt publica "La teoría política del mito» - primero como artículo suelto, y luego incorporado a su libro sobre el parlamentarismo, del mismo año-, y es allí donde el pensamiento de Sorel adquiere un protagonismo explícito.

El principal antecedente de una investigación acerca del vínculo entre Sorel y Schmitt lo constituye un agudo artículo de Luis Rossi, el cual muestra la filiación soreliana de la teoría política de Schmitt. ${ }^{2}$ En las líneas que siguen, intentamos desplegar el modo en que Sorel se inserta en el pensamiento de Schmitt. La argumentación se desplegará en dos momentos. Primero, realizaremos una lectura

\footnotetext{
${ }^{1}$ Como sostiene Galli, en la crítica a la mediación racionalista moderna -mediación común al liberalismo y al marxismo decimonónico- Schmitt se sirvió de autores contrarrevolucionarios pero también de pensadores eminentemente revolucionarios como Sorel. Cf. Galli (2011, p. 53).

${ }^{2}$ Cf. Rossi (1999). El autor destaca un núcleo de tres coincidencias básicas entre Carl Schmitt y Georges Sorel, a saber: a) la polemicidad de los conceptos; b) la antropologización del conflicto; c) un pathos bélico y heroico. A partir de estos elementos, Rossi entiende que el conflicto amigo-enemigo tiene una base concreta en el mito de la nación, y que dicho antagonismo se explica a partir de la amenaza al propio modo de vida que en esos años se vislumbraba en relación a Rusia. En este sentido, la lucha entre el mito de la nación y el mito de la lucha de clases constituye, en el decir de Rossi, la forma epocal que adopta la oposición amigo-enemigo. La apuesta de este artículo es desplegar y comentar algunos aspectos que permiten profundizar en la reinterpretación schmittiana de las ideas de Sorel. En particular, buscamos no descuidar la vinculación de la recuperación de Sorel con la crítica al pluralismo parlamentario, así como ver la adecuación de la teoría política del mito con el proceso de maduración de la conceptualización schmittiana acerca del fin de las neutralizaciones y la concurrente afirmación de la politización total.
} 
Carl Schmitt, lector de Georges Sorel.

La crítica al parlamentarismo, el mito de la nación y la «mirada rusa»

cercana del texto de Schmitt acerca del parlamentarismo, obra en la que el nacido en Plettenberg dedica un capítulo a reconstruir la teoría política del mito de Sorel. A partir de esa restitución, destacaremos que la recuperación de Sorel constituye un corolario ineludible al interior de este texto en vistas de la crítica al liberalismo y al bolchevismo. Segundo, intentamos esbozar la perduración implícita del mito nacional en la conferencia de Schmitt acerca de las neutralizaciones y las despolitizaciones, perduración que se muestra en el planteamiento schmittiano de un enfrentamiento vital.

\section{La crítica schmittiana al parlamentarismo y la teoría del mito de Sorel.}

Aunque Los fundamentos histórico-espirituales del parlamentarismo en su situación actual (1923) no sea una de las obras más citadas y restituidas de Schmitt, su importancia en la producción teórica del jurista alemán no es menor. Se inscribe en la prolífica e influyente serie de obras de la década de 1920, una época que se caracterizaba por un delicado contexto político nacional e internacional. En esos años, la publicación del texto sobre el parlamentarismo generó un importante debate en torno a la realidad institucional de la República de Weimar (Kennedy, 2008, p. 155 ss.).

En esta obra, Schmitt efectúa un análisis detenido de los principios del parlamentarismo, y los contrapone con la realidad política de su presente, con vistas a destacar la falta de adecuación de los primeros, formulados y aplicados a lo largo del siglo XIX, respecto de la segunda, la cual demandaría nuevas respuestas a nuevos problemas, tales como el advenimiento de la sociedad de masas, la formación de partidos políticos con grandes intereses particulares, y un contexto de posguerra. Schmitt diferencia parlamentarismo y democracia, destacando que el primero es un principio liberal, no necesariamente «democrático». En resumidas cuentas, lo que usualmente se ha destacado a la hora de leer este texto ha sido la crítica schmittiana al liberalismo, la propuesta de un concepto de democracia diferente, y la interpelación que estas reflexiones producirían en nuestro presente. 
Pero en su texto, además de referirse al parlamentarismo, Schmitt restituye la obra del complejo e irregular Sorel. Veamos, en lo que sigue, cada uno de estos elementos por separado.

\subsection{Parlamentarismo}

En la introducción a su obra, Schmitt destaca el que ha de ser el objetivo explícito y visible de su texto: "dar con el núcleo más profundo de la institución del Parlamento moderno» (Schmitt, 2008, p. 44). Puntualmente, esta búsqueda de un principio último se para en contra de las posturas que defienden el parlamentarismo a partir de argumentos técnicos y funcionales: según estos, el parlamentarismo sería válido porque, hasta ahora, ha funcionado, se ha mostrado relativamente eficaz, y es un «mal menor» frente a posturas más radicales. Pero ello no llegaría al fondo de las cuestiones y no podría abordar una respuesta en tiempos de crisis. En el decir de Schmitt, es necesario ir a las raíces, para poder así pasar «desde las cuestiones de índole táctica y técnica, a los principios intelectuales» (Schmitt, 2008, p. 45).

El diagnóstico de Schmitt es que la institución parlamentaria «ha perdido, moral e intelectualmente, las raíces en que se asentaba, y [...] se mantiene en pie como un aparato vacío, en virtud de una inercia meramente mecánica» (Schmitt, 2008, p. 44). ¿Cómo llega Schmitt a esta aseveración?

El autor destaca que la más antigua justificación del sistema parlamentario descansa en su carácter «expeditivo». Aunque es el pueblo quien, en su totalidad, debería decidir - como ocurría antiguamente, cuando era posible reunir a todos en un mismo lugar-, desde hace tiempo, y por razones prácticas, esa máxima ya no es factible. Surgió entonces la idea de que el pueblo eligiera una comisión de confianza, y en eso consistía el parlamento. No obstante, sostiene Schmitt, esta justificación es desde todo punto de vista insuficiente. Pues si de razones prácticas se tratara, también sería posible e igualmente admisible que una única persona de confianza, y no ya un cuerpo colegiado, decidiera en nombre del pueblo. El argumento técnico no puede estar, así, en la base del parlamentarismo. 
Carl Schmitt, lector de Georges Sorel.

La crítica al parlamentarismo, el mito de la nación y la «mirada rusa»

Asevera Schmitt que, en realidad, la esencia del parlamentarismo descansa en el principio de la "discusión pública» (öffentliche diskussion). La idea de fondo que subyace a esto es que, a partir del debate, las distintas "partículas de razón» que las personas expresan con sus argumentos, se agrupan y generan la «verdad». Esto hace del parlamentarismo un racionalismo de tipo específico: no absoluto como, por caso, el de la llustración, sino "relativo»: «[s]u justificación última, y su evidencia, vinculada a una época, se basan en que este racionalismo no es absoluto y directo, sino relativo en un sentido específico» (Schmitt, 2008, p. 75) ${ }^{3}$.

Para entender este racionalismo relativo, hay que mirar el parlamentarismo en su vinculación intrínseca con el liberalismo pues, según Schmitt, ambos van de la mano. Para el Jurist, debemos ser conscientes de que el liberalismo constituye un sistema metafísico con diversas facetas. El principio liberal de la «libre competencia» no se circunscribe solamente al campo económico: también se puede decir que «de la libre lucha de opiniones surge la verdad como de la lucha competitiva resulta, de suyo, la armonía social» (Schmitt, 2008, p. 75). El relativismo parlamentario implica decir que nunca habrá resultados definitivos acerca de la verdad - su metafísica renuncia a esa opción-, sino más bien una constante competencia que, a cada momento, la va configurando.

El hecho de que el liberalismo se autolimite a una verdad relativa tiene la consecuencia de que el equilibrio de opiniones sólo puede versar acerca de un conjunto de cuestiones que se asientan sobre un fundamento común no discutido ni susceptible de discutirse. El parlamentarismo, en este sentido, no es capaz de extender su capa a problemas de concepciones últimas del mundo. Ante las afirmaciones radicales, frente a las posturas absolutas y los casos decisivos, el Parlamento se paraliza. ${ }^{4}$

\footnotetext{
${ }^{3}$ Cf. supra, n. 1.

${ }^{4}$ Cf. Teología política (1922) y la recuperación de la crítica de Donoso Cortés hacia el liberalismo como «clase discutidora». En este punto, se ve cómo se repiten ciertas apreciaciones ya condensadas en obras previas. El liberalismo termina por caer en la inacción ante situaciones críticas. El enemigo en las cuestiones últimas termina siempre por ser el marxismo. Ante su amenaza, las instituciones liberales no pueden ser la respuesta para el jurista alemán. Cf. Schmitt (2001).
} 
Para Schmitt, en el momento en que se reconoce la centralidad de la discusión, se percibe también el significado auténtico de las dos exigencias políticas típicas del liberalismo: la publicidad y el equilibrio de poderes (Schmitt, 2008, p. 77). La publicidad surgió como oposición a la teoría de los secretos de Estado (arcana rei publicae), a «la idea de que en toda política debe haber un conjunto de [...] secretos concernientes a la técnica política» (Schmitt, 2008, p. 80). El equilibrio de poderes, por su parte, apareció para hacer frente al absolutismo. Ambos principios constituyeron, en conjunto, exigencias específicas que dieron nuevos caracteres a la vieja lucha general entre derecho y poder, entre la técnica política de Maquiavelo y un ethos moral y jurídico. En su evolución histórica, la publicidad habría de afirmarse como un valor absoluto en la Ilustración. El poder del déspota ilustrado encontraba un correctivo absoluto en la opinión pública, y, mientras ésta existiera, aquél podía expandir su poder sin límites. Jeremy Bentham y John Stuart Mill, en otras circunstancias y con diferentes presupuestos, habrían de defender este principio de la publicidad con igual énfasis.

El equilibrio de poderes encuentra su representación típica en la imagen de una balanza. En los tiempos modernos, la figura de la «balanza» es una de las más importantes y recurrentes del pensamiento político -en comparación con las imágenes del «Estado como maquinaria, el Estado como organismo, el Rey como clave de bóveda, como bandera o 'alma' de la nave» (Schmitt, 2008, p. 84). Aplicada al parlamento, la idea de una balanza en equilibrio encuentra dos puntos de anclaje: uno, al interior del propio parlamento - con la existencia de dos cámaras, con la presencia de varios partidos o simplemente con la competencia entre opiniones diversas-; el otro, entre los diferentes poderes del Estado, de los cuales el parlamento es sólo uno de ellos. En su evolución, las teorías sobre el equilibrio de poderes se han introducido en la teoría constitucional, y han llevado a que se identifique Constitución con división de poderes ${ }^{5}$.

Al igual que la publicidad y el equilibrio de poderes, el concepto de «ley» propio del parlamentarismo responde al mismo contexto histórico de lucha entre derecho y poder. En base a los monarcómacos, y en confrontación con la autoridad concreta del

\footnotetext{
${ }^{5}$ Desde este punto de vista, la dictadura aparece como el oponente de la separación de poderes, pues la suprime, y no de la democracia.
} 
Carl Schmitt, lector de Georges Sorel.

La crítica al parlamentarismo, el mito de la nación y la «mirada rusa»

rey, se alzó la idea de una ratio universal de la ley, y la exigencia de que a ella $-y$ no al Rey- es a quien debe en última instancia obedecerse. En el decir de Schmitt, esa contraposición subsiste y enfrenta lo general y lo particular, o, en otras, palabras, al concepto racionalista de una verdad relativa contra la defensa de la autoridad concreta tal como planteaba Hobbes ${ }^{6}$.

Según el parlamentarismo, mientras que la ley es considerada «algo intelectual», el ejecutivo es fundamentalmente acción, «obrar» (Schmitt, 2008, p. 95). Esta contraposición encuentra su forma más típica en The Federalist, en el cual se destaca la necesidad de que el ejecutivo sea ejercido por una sola persona, para que se mantenga la energía y la unidad de decisión, máxime en plausibles situaciones de crisis. Destaca Schmitt cómo el racionalismo relativo se autolimita y renuncia a extenderse al ejecutivo para no reducir «también a éste a un mecanismo de discusión». "Pues el racionalismo de este pensamiento sabe también mantener un contrapeso entre lo racional y lo irracional [...], siendo aquí también una mediación y, en cierto sentido, un compromiso [...]» (Schmitt, 2008, p. 97). Algo que sería inadmisible para el racionalismo absoluto francés que, de la mano de Condorcet, lleva a una dictadura de la razón. $Y$ algo que acontecería de forma también diferente en Alemania, donde la teoría del equilibrio de poderes se vinculó con una idea de la mediación orgánica y no mecánica.

En conjunto, lo restituido hasta aquí da forma a los principios del parlamentarismo. El esfuerzo de Schmitt consiste en demostrar que dichos principios se encuentran aunados al sentir de una época: el siglo XIX, y que este sentir epocal se expresa como una profunda «fe en la discusión pública». Para el pensador alemán, la situación histórica que hizo posible el desenvolvimiento de los principios del parlamentarismo se encuentra problematizada en su presente. El siglo XX ha traído consigo cambios profundos que han llevado a que la fe en el parlamentarismo se vea embestida desde varios frentes. En el decir de Schmitt, las grandes decisiones políticas ya no surgen de un debate parlamentario, sino que son tomadas en secreto por los

\footnotetext{
${ }^{6}$ Cf. Teología política, Teoría de la Constitución (1928) y «Sobre los tres modos de pensar la ciencia jurídica» (1934), donde se desarrolla la evolución histórica de estas concepciones jurídicas y la discusión de Schmitt con el normativismo y el positivismo (Schmitt, 2001, 2011, 2012).
} 
poderes sociales indirectos. Los debates, si es que los hay, ya no se dan en el pleno del parlamento, sino en comisiones. La propia responsabilidad parlamentaria ha terminado por suprimir la división de poderes, contra la vieja idea del parlamentarismo.

Recopila Schmitt:

Puede que, en la práctica, no quepa otra opción. Pero al menos se ha de tener suficiente conciencia de la situación histórica para poder ver que el parlamentarismo renuncia, con ello, a su base conceptual y pierde su ratio todo ese sistema de libertad de opinión, reunión y prensa, de sesiones públicas e inmunidades y privilegios parlamentarios. Comisiones reducidas o reducidísimas de partidos o coaliciones de partidos deciden a puerta cerrada, y lo que acuerdan los representantes de los intereses del gran capital en un reducidísimo comité acaso resulte aún más importante para la vida cotidiana y el destino de millones de personas que las decisiones políticas (Schmitt, 2008, p. 105).

Esta crisis de la fe en la discusión pública hace que la institución parlamentaria vea socavado su soporte y problematizado su sentido actual. Si es despojado de sus principios últimos y sólo queda como mero instrumento técnico -argumentará Schmitt en 1926-, "sólo se precisará mostrar via facti [...] que las cosas también pueden ir de otra manera, y entonces el Parlamento quedará liquidado» (Schmitt, 2008 , p. 22). La pregunta que permanece latente, entonces, es si hay algún reemplazo posible al parlamentarismo.

Hasta aquí vimos, entonces, que la reconstrucción schmittiana de los fundamentos del parlamentarismo se desarrolló en varios pasos. El autor, desechando previamente cualquier justificación de índole técnica, entiende que el núcleo espiritual del parlamentarismo puede hallarse en el principio de discusión pública. A partir de este principio, por un lado, se despliega el carácter eminentemente relativo del racionalismo liberal y, por otro lado, adquieren su sentido característico los otros dos elementos centrales de la idea parlamentaria: la publicidad y el equilibrio de poderes. Expuestas estas ideas, Schmitt enuncia la inadecuación de los principios del 
Carl Schmitt, lector de Georges Sorel.

La crítica al parlamentarismo, el mito de la nación y la «mirada rusa»

parlamentarismo con la situación histórica de Weimar, en una situación donde la democracia de masas ha hecho de la discusión basada en argumentos un mero formalismo. Ahora bien, concomitantemente al agotamiento de este racionalismo decimonónico - tanto en su variante liberal como hegeliano-marxista-, puede identificarse la emergencia de una filosofía irracionalista de la acción directa, expresiva de las nuevas corrientes vitalistas en auge, que se contrapone de manera decisiva a estos resguardos racionalistas y vehiculiza una mirada radicalmente diferente sobre lo político. Para dar cuenta de ellas, Schmitt recupera las reflexiones de Georges Sorel sobre la violencia revolucionaria y el mito de la huelga general.

\subsection{El mito y lo político}

Schmitt recupera la obra central de Georges Sorel: Reflexiones sobre la violencia (Sorel, 2005), la cual «expone con la mayor claridad el contexto histórico e intelectual» de las teorías irracionalistas (Schmitt, 2008, p. 134). Si Benedetto Croce había dicho, a costa de Sorel, que las ideas democráticas habían triunfado en el imaginario del proletariado, los acontecimientos de Rusia e Italia volvían a darle una oportunidad al francés, según Schmitt.

Sorel encontraría sus ancestros espirituales en Proudhon, Bakunin ${ }^{7}$ y Bergson:

Para Proudhon y para Bakunin, el anarquismo significa una lucha contra toda forma de unidad sistemática, contra la uniformidad centralizadora del Estado moderno, contra los políticos que hacen del Parlamento su profesión, contra la burocracia, el aparato militar y policial, contra la fe en Dios, que ellos viven como un centralismo metafísico. [...] Cualquier sistema completo forzaría de forma violenta la individualidad concreta, la realidad social de la vida. El fanatismo uniformador de la llustración no sería menos despótico que la unidad y la identidad de la democracia moderna (Schmitt, 2008, pp. 135-136).

\footnotetext{
7 Resulta por demás llamativo que Schmitt nombre a Bakunin cuando en las Reflexiones sobre la violencia no es nombrado. Proudhon y Bergson, por el contrario, aparecen allí de forma recurrente.
} 
Para Schmitt estos autores, desde la vida concreta de la clase trabajadora, han reconocido la importancia de los sindicatos y su específico instrumento de lucha: la huelga. Han creado la tradición donde Sorel, junto con la filosofía de Bergson, se asienta. El centro de los pensamientos de Sorel está constituido por una teoría del mito, la cual representaría, en el decir de Schmitt, el antagonismo más fuerte tanto con el racionalismo absoluto de la llustración y el marxismo decimonónico como con el racionalismo relativo del parlamentarismo liberal.

El contexto de la producción de Sorel está marcado por la crítica del socialismo parlamentario. Sostiene el francés: «Frente a ese socialismo ruidoso, charlatán y mendaz [...] se yergue el sindicalismo revolucionario que, por el contrario, se afana por que nada quede indeciso [...]» (Sorel, 2005, p. 175). El sindicalismo utiliza medios de expresión que «resaltan todo el valor de las fuerzas puestas en juego» (Sorel, 2005, p. 176). Para ello no basta el lenguaje, sino que «hay que apelar a conjuntos de imágenes, capaces de evocar, en conjunto y por mera intuición, antes de cualquier análisis reflexivo, la masa de los sentimientos que corresponden a las diversas manifestaciones de la guerra entablada por el socialismo contra la sociedad moderna» (Sorel, 2005, p. 176).

Y continúa:

Para actuar, sin embargo, no podemos menos de salirnos del presente, y razonar acerca de ese porvenir que parece condenado a quedar siempre fuera de nuestra razón. La experiencia nos hace ver que ciertas construcciones de un porvenir indeterminado en el tiempo pueden poseer gran eficacia y muy pocos inconvenientes, cuando son de determinada naturaleza; lo cual se produce cuando se trata de mitos en los que se manifiestan las más fuertes tendencias de un pueblo, de un partido o de una clase; tendencias que se ofrecen a la mente con la insistencia de instintos en todas las circunstancias de la vida, y que confieren un aspecto de plena realidad a unas esperanzas de acción próxima en las cuales se basa la reforma de la voluntad (Sorel, 2005, p. 178). 
Carl Schmitt, lector de Georges Sorel.

La crítica al parlamentarismo, el mito de la nación y la «mirada rusa»

Lo importante de un mito no es el carácter verdadero de su contenido ni su concreción en la trama de la historia. Por el contrario, Sorel nos muestra que los grandes mitos nunca produjeron lo que pregonaban: los primeros cristianos no vieron realizado el mito apocalíptico, pero éste los había movilizado a acciones que redundaron en su provecho. Sorel da ejemplos similares en el caso de los protestantes, de la Revolución Francesa y de la unificación italiana. «Hay que juzgar a los mitos como medios de actuar sobre el presente: toda discusión acerca de cómo aplicarlos materialmente al transcurso de la historia carece de sentido» (Sorel, 2005, p. 180).

La apuesta de Sorel es demostrar que el proletariado tiene un mito: la huelga general. No es el significado, el contenido o la caracterización de la huelga general lo relevante aquí, sino la «fe» que ella despierta en el proletariado. Sólo con fe se pueden exigir los mayores sacrificios y esperar la generación de una nueva moral.

El mito es absoluto, jamás algo «relativo». Por ello, toda idea de discusión y consenso es vinculada por Sorel con el intelectualismo burgués. A la imagen liberal de la balanza en equilibrio se le contrapone «la representación bélica de una sangrienta, definitiva y decisiva batalla de aniquilación» (Schmitt, 2008, p. 140), según Schmitt.

1848 expresaría esta batalla con sus bandos respectivos: Donoso Cortés y Proudhon. Ambos van a las cuestiones últimas, a las respuestas decisivas. Ambos poseen una teología. La tensión entre los antagonismos adquiere un carácter escatológico: «A diferencia de lo que sucedía en la tensión dialécticamente construida del marxismo hegeliano, aquí se trata de antagonismos directos e intuitivos entre diversas imágenes míticas» (Schmitt, 2008, p. 141) ${ }^{8}$.

El mito soreliano, a su vez, se diferencia de la utopía y de la dictadura. Ambos son la expresión de un intelectualismo uniformador que niega la libertad del individuo. Esto no es óbice para exigir, simultáneamente, "la disciplina y la moral más férreas» (Schmitt, 2008, p. 144). La dictadura es expresión del pensamiento técnico del racionalismo. La violencia revolucionaria puede ser bárbara, pero jamás sistemáticamente cruel e inhumana como la dictadura. La «dictadura del proletariado»

\footnotetext{
8 Schmitt, siguiendo en mucho a Sorel, destaca que Marx sigue atado a «la sobrevaloración intelectualista de la educación burguesa de Occidente». Estas insuficiencias de Marx, su anclaje en la tradición occidental, habían sido destacadas por Sorel (2005, p. 237).
} 
cabe dentro de esta apreciación. Es un regreso al jacobinismo de 1793. Constituye un resabio de la estructura conceptual del ancien régime. Reemplaza un aparato burocrático y militar por otro. ${ }^{9}$ Pero, de nuevo, la respuesta a este racionalismo absoluto no es un racionalismo relativo. La respuesta a la «fuerza» del aparato represivo es la «violencia» creadora de las masas subyugadas (Sorel, 2005, pp. 230231).

Para proseguir su argumentación, Schmitt debe remarcar una serie de «contradicciones» de Sorel, debidas a «carencias orgánicas» (Schmitt, 2008, p. 147). Sorel se sigue manteniendo en una perspectiva económica, basándose en la centralidad de la producción. Esto hace que sea la burguesía la que defina «el terreno donde se ha de luchar, e incluso las armas de lucha, es decir, la estructura de la argumentación». Si Sorel permaneciera solamente en este terreno -argumenta Schmitt-, «si el mecanismo sigue adelante, si la producción continúa creciendo, el proletariado tendrá que renunciar a su mito. Exactamente al igual que la burguesía, el predominio del mecanismo de producción le precipitará a entrar en un estadio racionalista carente de mitos» (Schmitt, 2008, p. 148). Pero al introducir lo irracional, en Sorel se alberga la posibilidad de romper a golpes este esquema.

La imagen mitológica del burgués ha contribuido a ofrecer un blanco donde todos los afectos de odio podían cristalizarse. Para Marx y Engels, el burgués es el último representante de una humanidad prehistórica, el último enemigo de la humanidad. De este modo, la inhumanidad del burgués le permite a Marx «hacer surgir, como su contrario, la necesidad inmediata de lo bueno y absolutamente humano» (Schmitt, 2008, pp. 124-126) ${ }^{10}$.

\footnotetext{
${ }^{9}$ Cf. Sorel (2005, p. 227).

${ }^{10}$ Añade Schmitt: «De ahí que, desde una perspectiva marxista, del proletariado sólo pueda decirse que es, de forma absoluta, la negación de la burguesía, o que sería propio de un socialismo no científico el imaginarse el aspecto que tendrá el Estado proletario del futuro. Es una necesidad sistemática que todo lo concerniente al proletariado sólo pueda ser determinado negativamente. Lo único que puede decirse de la sociedad del futuro es que en ella no habrá antagonismos de clases, y del proletariado que es la clase social que no participa de la plusvalía, que no es poseedora de cosas, que no conoce ni familia ni patria, etc. El proletariado no es, socialmente, nada. De él cabe decir que, al revés que el burgués, no es nada más que un ser humano, de lo que se deriva, con una necesidad dialéctica, que durante el tiempo de transición no debe ser más que el miembro de su clase, es decir, que tiene que quedar absorbida por algo que constituye lo contrario de lo humano: la clase. El antagonismo de clases tiene que convertirse
} 
Carl Schmitt, lector de Georges Sorel.

La crítica al parlamentarismo, el mito de la nación y la «mirada rusa»

Cuando esta imagen, con todo ese trasfondo histórico y metafísico, se expandió hacia el este, se fundió con el «odio ruso contra la complicación, la artificialidad, el intelectualismo de la civilización occidental» (Schmitt, 2008, p. 149).

La Revolución Rusa y el ascenso de los bolcheviques al poder son temas recurrentes en la producción schmittiana de estos años. Rusia se constituye en un enemigo por antonomasia de los escritos del jurista. Acontece allí una coincidencia de varios fenómenos que separan a Rusia de la tradición europeo-occidental y que dan intensidad a esta oposición. A pesar de que los bolcheviques manifiesten su deuda con la dialéctica hegeliana, e incluso a pesar de que bajo su dominación hayan reprimido a los anarquistas, su argumentación «contiene razonamientos de corte decididamente anarcosindicalistas» (Schmitt, 2008, p. 132). De forma análoga a lo relatado en Catolicismo romano y forma política (Schmitt, 2009, pp. 89-92), Schmitt considera que el marxismo pudo echar fuertes raíces en suelo ruso debido a que esta filosofía se veía libre, allí, de toda atadura a las tradiciones de Europa occidental; y a que allí encontraron una realización las nuevas ideas de corte irracionalista. A diferencia de lo acontecido en 1848, cuando Proudhon y Donoso Cortés se enfrentaron hasta las últimas consecuencias pero ambos se mantuvieron dentro de la tradición europeooccidental, lo que parece ocurrir hoy día es un enfrentamiento, no ya al interior de Europa occidental, sino entre ésta y el eslavismo ruso. En este punto resulta importante saber si Sorel sirve o no a la causa occidental, y si se lo puede considerar como parte de esta tradición, del mismo modo que Schmitt considera que Marx y Engels son parte de ella.

Aunque Schmitt titula el último apartado del capítulo final «Mitos de la lucha de clases y mitos nacionales en el antagonismo entre bolchevismo y fascismo», mostrando una lucha entre estos dos mitos, desde el comienzo da por triunfador al mito nacional en ambos países. El mito de la lucha de clases termina siendo derrotado. Por ello no es raro que el jurista alemán destaque que la imagen del burgués, en Rusia, fue inmediatamente dominada por otra: una imagen mítica de «fuertes elementos nacionales» (Schmitt, 2008, p. 150). En su apéndice «En defensa de Lenin» Sorel

en un antagonismo absoluto a fin de que todos los antagonismos puedan ser absolutamente superados y desaparecer en lo puramente humano» (Schmitt, 2008, pp. 125-126). 
reivindica que, con la revolución, Rusia volvía a ser rusa, y exaltaba a Lenin como exponente del moscovismo. De forma que esta energía nacional ya habría estado presente originalmente en Sorel ${ }^{11}$. Los ejemplos que el francés da -las guerras durante la Revolución Francesa, las guerras española y alemana contra Napoleónson de carácter nacional ${ }^{12}$.

El mito nacional y el mito de la «lucha de clases» pueden coincidir, como en Rusia y en Irlanda, lo cual nada dice acerca de la potencia específica de cada uno de ellos por separado. Pero donde ellos se enfrentaron -en Italia- es posible dar un veredicto: el triunfador ha sido el mito nacional. «Hasta el momento hay sólo un único caso donde, invocando el recurso al mito, fueron dejados despectivamente de lado la democracia y el parlamentarismo, y eso ha sido un ejemplo de la fuerza irracional del mito nacional» (Schmitt, 2008, p. 152).

La difusión y la fuerza que la idea de mito presenta en la realidad presente sería un síntoma de la pérdida de validez del parlamentarismo. Pero el mito, creado para combatir la autoridad, produjo, sin quererlo, "una nueva autoridad, un nuevo sentimiento de orden, disciplina y jerarquía» (Schmitt, 2008, p. 153) ${ }^{13}$. Aquí se encuentra la vuelta argumentativa central, que le permite a Schmitt apropiarse plenamente de la teoría del mito. Todos los pasos previos perderían su fuerza y sentido sin este corolario. La teoría del mito es apropiada por Schmitt en contra del propio Sorel. Ya no sirve para movilizar al proletariado a la libertad y al dominio de la

\footnotetext{
${ }^{11}$ Aunque Schmitt intenta mostrar esta presencia de elementos nacionales en Sorel, la cuestión se presenta de una forma más compleja. En sus Reflexiones sobre la violencia, a pesar de que los ejemplos de Francia, España y Alemania están presentes y ponderados, también es cierto que hay una explícita reivindicación del «antipatriotismo». Es probable que esa postura haya cambiado en los años siguientes y que, para el momento en que el francés escribió su Pour Lenine (1919), el elemento nacional estuviera presente. De por sí, la discusión sobre este tópico en la obra soreliana amerita un debate que excede los límites de la presente reflexión, centrada sobre las reapropiaciones efectuadas por Schmitt.

${ }^{12}$ En una caracterización que sería típica y relevante en obras posteriores, Schmitt destaca aquello que definiría el ser nacional: «En el sentimiento de lo nacional operan distintos elementos de una manera sumamente distinta en los diferentes pueblos: las ideas más naturales sobre la raza y el origen, un "terrisme" que parece típico de las tribus céltico-romanas; y, luego, la lengua, la tradición, la conciencia de una cultura y una educación común, así como la conciencia de una comunidad de destino, y una sensibilidad respecto al ser distinto de los demás, todo eso se mueve hoy más bien en dirección de lo nacional que de los antagonismos de clase» (Schmitt, 2008, pp. 150-151).

${ }^{13}$ Aquí se plantea algo similar a lo que ocurre hacia el final de Teología política, cuando se destaca que Bakunin es el «dictador de la antidictadura» (Schmitt, 2001, p. 62).
} 
Carl Schmitt, lector de Georges Sorel.

La crítica al parlamentarismo, el mito de la nación y la «mirada rusa»

producción, sino a engendrar un nuevo tipo de autoridad y de validez, que pondera la inclusión de un aspecto irracional a la hora de legitimarse.

Hasta aquí, entonces, hemos intentado extractar algunos de los argumentos generales que Schmitt presenta y considera en su libro sobre el parlamentarismo. A partir del esbozo que emprendimos, podemos realizar una serie de consideraciones elementales.

En sintonía con su producción previa y posterior, Schmitt intenta mostrar las limitaciones del liberalismo en relación con el orden político. En el caso del parlamentarismo, los principios histórico-espirituales que le dieron nacimiento -la discusión, la publicidad, el equilibrio de poderes - se encuentran hoy en crisis ante la nueva realidad social. Aunque Schmitt no explicita cuáles son los elementos que darían cuenta del radical cambio social acontecido, parece claro que intenta mostrar la vejez del esquema liberal Estado-sociedad civil luego de profundos cambios como el advenimiento de la sociedad de masas, la Gran Guerra y la Revolución Rusa. El racionalismo relativo del sistema parlamentario no puede dar una respuesta clara ante situaciones decisivas, y no puede, por tanto, estar a la base de un orden político que aspire a superar exitosamente los desafíos del presente.

Frente al racionalismo relativo, Schmitt recupera el concepto de mito de Sorel. Esta «teoría irracionalista» encerraría otros principios no tenidos en cuenta hasta ahora. Resulta llamativo el hecho de que el alemán haya decidido recuperar la obra de un francés anarcosindicalista, que plantea la revolución socialista y que pregona el «antipatriotismo». Sin embargo, Schmitt, como vimos, también opera un cambio a la hora de recibir esta obra. Pues si siguiera a Sorel al pie de la letra, tendría que admitir que la respuesta al parlamentarismo es el socialismo. Pero Schmitt, desde ya, no puede aceptar esto. La vuelta de tuerca consiste en que el jurista pretende usar al propio Sorel para quebrar la tesis socialista. En una lectura específica, saca a relucir la noción de «mito nacional», la cual timonea los argumentos de embate contra el liberalismo y permite esmerilar al enemigo profundo que alienta la elaboración schmittiana en estos años: el espíritu encarnado en la experiencia rusa, frente al cual resulta imperioso aglutinar el bando propio. 
Bajo este punto de vista, entonces, se debe entender que esta obra contiene mucho más que una crítica al parlamentarismo liberal. En un primer paso, la consideración de que la fuerza del liberalismo y del marxismo no reside en «cuestiones técnicas», sino en principios y una "fe», permite pulimentar el estatus político de sus adversarios. La posterior deconstrucción de esos principios lleva no sólo a la problematización de sus pretensiones de verdad respectivas, sino a la acuciante pregunta sobre cómo dar contestación a la crisis del presente. Si la respuesta no reside en el parlamentarismo ni en el marxismo, es necesario encontrar un canal de expresión para los valores y la configuración de un principio político movilizador. Si ello es así, si hay un trasfondo más profundo en torno a la búsqueda de nuevos criterios para nuevos desafíos, entonces la recuperación de Sorel constituye un corolario ineludible al interior de este texto.

En lo que resta del artículo, queremos mostrar la perduración del tópico soreliano en la conferencia La era de las neutralizaciones y de las despolitizaciones, obra en la que se incluye una lectura de la evolución europea moderna que permite entender la reactualización de Sorel en el marco del esbozo schmittiano acerca del carácter total que ha adquirido lo político en el siglo XX.

2. «Bajo la mirada de los rusos»: la conferencia de 1929 , el fin de las neutralizaciones y el enfrentamiento vital

La conferencia «La era de las neutralizaciones y de las despolitizaciones», brindada en 1929 en Barcelona y publicada en 1932 junto con la reedición de El concepto de lo político ${ }^{14}$ comienza con una aseveración vehemente y enigmática a la vez: «vivimos sous I'oeil des Russes [bajo la mirada de los rusos]». Enseguida, Schmitt añade que los rusos «[p]oseen suficiente vitalidad como para apoderarse de nuestros conocimientos y de nuestra técnica y usarlos como armas» (Schmitt, 2006, p. 107). En estas líneas puede ya observarse la permanencia del enfrentamiento con Rusia en la pluma de Schmitt. El Jurist sostiene:

\footnotetext{
14 Para un detallado comentario acerca de los cambios en las ediciones de El concepto de lo político y de esta conferencia de 1929, cf. Meier (2008).
} 
Carl Schmitt, lector de Georges Sorel.

La crítica al parlamentarismo, el mito de la nación y la «mirada rusa»

Los rusos se tomaron el siglo XIX europeo al pie de la letra, reconocieron lo que constituía su núcleo mismo y extrajeron de sus premisas culturales las últimas consecuencias. Siempre se vive bajo la mirada del hermano más radical, el que le obliga a uno a llegar hasta las últimas consecuencias prácticas (Schmitt, 2006, p. 108).

En Rusia ve Schmitt la consumación de la evolución moderna, cuyo resultado es que allí «ha nacido un Estado que es más estatal de lo que pudo serlo jamás el Estado del más absoluto de los príncipes». La situación planteada con Rusia, la observación del hermano más radical, «muestra, en su versión más extrema, lo que constituye el núcleo de la historia moderna de Europa» (Schmitt, 2006, p. 108).

Schmitt entiende que el espíritu europeo moderno ha recorrido una serie de etapas, cada una de las cuales se distingue de las demás por el hecho de que posee un ámbito central específico. Son cuatro grandes movimientos, cada uno correspondiente a un siglo: de lo teológico a lo metafísico, en el siglo XVII; de lo metafísico al moralismo humanitario, en el siglo XVIII; del moralismo humanitario a la economía, en el siglo XIX; y la provisional situación del siglo XX, caracterizada por el dominio de la técnica ${ }^{15}$.

Ahora bien, el punto importante que explica estos desplazamientos es que cada uno de ellos constituyó un intento por encontrar una arena neutral, en la cual cesara el conflicto. En el principio, frente a las luchas teológicas del siglo XVII, se creyó ver en la metafísica natural un terreno fértil donde se acabaran las disputas y todos pudieran entenderse ${ }^{16}$.

El problema es que, una vez producido el desplazamiento y lograda la neutralización, el flamante centro de gravedad se volvía fuente de nuevos

\footnotetext{
${ }^{15}$ Schmitt indica que estos desplazamientos no deben ser leídos en clave evolutiva, como si se tratase de un «progreso» del espíritu europeo -ni tampoco como su contrario: un «retroceso»-. Asimismo, el autor añade que también resulta erróneo «interpretar la secuencia de etapas como si en cada uno de esos siglos no hubiese habido nada más que ese centro de gravedad. Lo que existe siempre es más bien una cierta coexistencia pluralista de etapas que ya han sido recorridas [...] y por ejemplo el Berlín actual está más cerca, medido en distancia cultural, de Nueva York o de Moscú que de Munich o de Tréveris. El desplazamiento de los ámbitos centrales se refiere pues tan sólo al hecho concreto de que en estos cuatro siglos de historia europea han ido cambiando las élites dirigentes» (Schmitt, 2006, pp. 109-110).

${ }^{16}$ Es menester destacar que para Schmitt el paso de la teología a la metafísica natural fue el desplazamiento decisivo y de mayor impacto, que habría de determinar el curso de los siglos posteriores.
} 


\section{German Rodrigo Aguirre}

enfrentamientos, obligando a realizar un nuevo desplazamiento hacia otra esfera del espíritu:

Sin embargo, la dialéctica de una evolución de esta clase hace que cada vez que se desplaza el centro de gravedad surja un nuevo terreno de disputa. [...] En Europa la humanidad está siempre saliendo de un campo de batalla para entrar en un terreno neutral, y una y otra vez el recién alcanzado terreno neutral se vuelve nuevamente campo de batalla y hace necesario buscar nuevas esferas de neutralidad (Schmitt, 2006, pp. 116-117).

Schmitt entiende que, en su presente, hay una fe profunda en que la técnica constituye la nueva esfera neutral, y que esa esfera es la definitiva. En la técnica se observa una objetividad inexpugnable, y de ella se espera lograr la convivencia pacífica de los hombres. Para nuestro autor, no obstante,

la neutralidad de la técnica no se parece a la neutralidad de ninguno de los ámbitos anteriores. La técnica es siempre sólo instrumento y arma, y porque sirve a cualquiera no es neutral. De la inmanencia de lo técnico no sale una sola decisión humana ni espiritual, y mucho menos la de la neutralidad (Schmitt, 2006, p. 118).

En otras palabras, caen en un error los hombres que esperan de la técnica un perfeccionamiento humanitario y moral, no sólo porque «están vinculando técnica y moral de forma mágica», sino porque presuponen que ella será utilizada sólo en el sentido que ellos le darían. La realidad indica otra cosa: la técnica puede ser usada para fines buenos o malos, pero de ella misma no puede extraerse bondad o maldad alguna.

En el decir de Schmitt, la generación que lo precedió encontró en la técnica la desesperante señal de un ocaso cultural. Ernst Troeltsch, Max Weber y Walter Rathenau, entre otros, son exponentes de ese sentimiento que veía en la técnica el arribo de la «nada espiritual». Para el Jurist, dicho temor no era otra cosa que el titubeo de esta generación para «poner a su servicio el grandioso instrumental de la 
Carl Schmitt, lector de Georges Sorel.

La crítica al parlamentarismo, el mito de la nación y la «mirada rusa»

nueva técnica, a pesar de que éste no espera otra cosa que alguien que se sirva de él» (Schmitt, 2006, p. 120).

Si la técnica no es más que un instrumento desprovisto de espíritu, y si de ella no es factible deducir una sola orientación política, lo que resulta es que hay una diferencia irreductible entre técnica y fe en la técnica. La primera es neutral en un sentido no político, pues no contiene ninguna decisión concreta; la segunda es eminentemente política, aunque considere ser portaestandarte de la despolitización. Para Schmitt, la religión de la tecnicidad "ha conducido al credo masivo de un activismo antirreligioso [...]; puede que sea un espíritu maligno y demoníaco, pero lo que no se puede es rechazarlo como mecanicista...» (Schmitt, 2006, p. 120).

En el decir de Schmitt, es sobre todo el Estado el que adquiere su especificidad según los variantes centros de gravedad. Las agrupaciones amigo-enemigo están determinadas por referencia al ámbito central de una época. «Todos los conceptos de la esfera del espíritu, incluido el concepto mismo de espíritu, son en sí mismos pluralistas, y se entienden únicamente a partir de la existencia política concreta» (Schmitt, 2006, p. 112) $)^{17}$. La historicidad conceptual hace que el ámbito espiritual central de cada época otorgue inteligibilidad a los conceptos: por un lado, «los procesos y acontecimientos que producen alguna impresión en la vida interior del hombre, y que se convierten así en objeto de su reflexión y de sus conversaciones» (Schmitt, 2006, p. 112), se jerarquizan a partir del centro de gravedad epocal. Por otro lado, cada concepto adquiere su significado característico a partir del centro de gravedad de cada época.

Así, cuando lo teológico era lo decisivo, la expresión cuius regio eius religio tenía peso político; pero cuando lo teológico dejó de ser el centro de gravedad, dicho principio perdió toda importancia. Se desplazó al ámbito cultural, primero -cuius regio eius natio- para terminar en el económico - cuius regio eius oeconomiadonde pasó a significar que dentro de un mismo Estado no pueden coexistir dos

\footnotetext{
17 Aquí se muestra algo ya presente en el Schmitt de 1922 - momento en que se publicaba su celebérrima Teología política-, consistente en la afirmación de la historicidad y la plurivocidad de los conceptos. Su sociología de los conceptos sería un claro antecedente e inspiración para la historia conceptual de Reinhart Koselleck $(1993,2007)$.
} 
sistemas económicos opuestos. Hoy día, es el Estado soviético el que ha llevado a la práctica de manera más cabal el principio cuius regio eius oeconomia.

El punto que quiere remarcar Schmitt es que un Estado debe ser capaz de reconocer la propia época histórica:

Tiene que hacer suya la pretensión de reconocer correctamente el conjunto de la evolución histórica. Es ahí donde estriba su derecho a gobernar. Un Estado que en plena era económica renunciase a comprender y guiar apropiadamente por sí mismo las circunstancias económicas tendría que declararse neutral respecto de las cuestiones y decisiones políticas, con lo cual abandonaría también su pretensión de gobernar (Schmitt, 2006, p. 115).

Hay aquí una clara referencia a la situación que estaba viviendo la República de Weimar, donde el pluralismo de los partidos políticos impedía formar una voluntad política unívoca y, por el contrario, dificultaba toda decisión. Siguiendo el planteo schmittiano respecto de la evolución moderna que decantó en la técnica, y entendiendo la antedicha apreciación acerca del rol del Estado para interpretar correctamente la propia situación histórica, surge la pregunta: ¿cuál es, entonces, la situación concreta del presente?

Pues bien, para la apreciación schmittiana, en su presente ya no quedan nuevas esferas donde hallar la neutralidad. La técnica, como se ha dicho, no es un terreno neutral en el sentido de las anteriores esferas, sino sólo instrumento a disposición de quien quiera usarlo. La evolución europea de neutralización y despolitización es, al mismo tiempo, la politización progresiva de todas las esferas, puesto que cada nuevo terreno neutral fue contagiado de politización. Cuando ya no quedan esferas neutrales, estamos ante la constatación de que todo en potencia se ha vuelto político. La constatación de Schmitt es que la politización ha adquirido un carácter total: ha invadido todos los ámbitos humanos. Su esfuerzo consistirá en reubicar las energías 
Carl Schmitt, lector de Georges Sorel.

La crítica al parlamentarismo, el mito de la nación y la «mirada rusa»

políticas para lograr la unidad estatal en el contexto del advenimiento de lo que, a partir de 1930, denominará Estado total ${ }^{18}$.

El proceso de neutralización progresiva de los diversos ámbitos de la vida cultural ha llegado a su fin porque ha llegado a la técnica. La técnica no es ya un terreno neutral en el sentido de aquel proceso de neutralización, y toda política fuerte habrá de servirse de ella. Por eso concebir nuestro siglo en un sentido espiritual como la era técnica no puede tener más que un sentido provisional. El sentido definitivo se hará patente cuando quede claro qué clase de política adquiere suficiente fuerza como para apoderarse de la nueva técnica, y cuáles son las verdaderas agrupaciones de amigo y enemigo que prenden sobre este nuevo suelo (Schmitt, 2006, p. 121).

El cierre de la conferencia de Schmitt manifiesta el reconocimiento de que el centro de gravedad de la existencia humana no puede ser un dominio neutral, puesto que hay un «pluralismo de la vida espiritual». En virtud de dicho pluralismo, es erróneo entender los antagonismos en términos de la oposición entre mecánico y orgánico ${ }^{19}$, 0 entre muerte y vida. Aquí, el aire vitalista que muestra Schmitt es claro:

Una vida que no tenga frente a sí más que la muerte ya no es vida, no es sino impotencia e inanidad. [...] Una agrupación que vea de su lado sólo espíritu y vida, y del otro sólo muerte y mecánica, no significa ni más ni menos que la renuncia a la lucha, y no posee otro valor que el de una queja romántica. Pues la vida no lucha con la muerte, ni el espíritu con la falta de él. El espíritu lucha contra el espíritu, la vida contra la vida, y es de la fuerza de un saber íntegro de donde nace el orden de las cosas humanas. Ab integro nascitur ordo (Schmitt, 2006, pp. 121-122).

\footnotetext{
${ }^{18}$ En este punto, Ricardo Laleff Ilieff, indica que la conferencia de 1929 «puede ser catalogada como un antecedente del Estado total, puesto que recién Schmitt utilizará dicha categoría tras conocerse el trabajo de Ernst Jünger de 1930 llamado La movilización total» (Laleff Ilieff, 2015, p. 38). Asimismo, respecto de la conceptualización del Estado total y la tipología de Estados de Schmitt en el último período de Weimar, véase Ricci Cernadas (2014).

${ }^{19}$ En 1960, Schmitt realiza una particular lectura acerca de la vinculación orgánico-mecánico en relación al impacto de las «distinciones bimembres» en la historia alemana reciente, puntualmente la oposición entre comunidad y sociedad. Véase Schmitt (2014).
} 
Esa impronta vitalista se mantiene en línea con las ideas mantenidas en la recuperación de la teoría del mito de Sore ${ }^{20}$. Schmitt constata que hay un enfrentamiento entre diferentes formas de existencia vital y que, en la época actual, no hay neutralización posible. El carácter total de lo político se muestra ya inevitable, desde el momento en que todas las esferas de la vida y acción humana se han politizado: el Estado ya no puede separarse de la sociedad, y en esta conferencia se evidencia ya un preludio del Estado total que Schmitt desarrollará a partir de 1930.

En la politización total, la movilización del mito nacional es la fuerza que permite aglutinar y discernir los bandos amigo-enemigo. En este lugar, la movilización de las energías nacionales permite a Schmitt hacer una doble llamada de atención: por un lado, para hacer frente al pluralismo interior, que disgrega la unidad política; por otro lado, para aglutinar al bando propio y hacer frente al gran antagonista espiritual: el «hermano radical» ruso, que ya había llevado a término las consecuencias prácticas del devenir neutralizador de la Europa moderna.

\section{Consideraciones finales}

En conjunto, la presente reflexión intentó desplegar el modo en que Carl Schmitt se acercó y resignificó el pensamiento de Georges Sorel. Para eso, propusimos en primer término hacer una lectura cercana del texto del Jurist acerca del parlamentarismo obra en la cual Sorel adquiere un explícito protagonismo-, con vistas a identificar la inserción de la teoría del mito del francés en el acervo de argumentos contenidos en dicha obra. Partiendo del análisis de la institución parlamentaria, identificamos, siguiendo a Schmitt, la enunciación de los principios de discusión pública, publicidad y equilibrio de poderes, que daban forma a un racionalismo de tipo relativo característico del pensamiento liberal.

Posteriormente, nos detuvimos en la apropiación schmittiana de Sorel. Vimos que, en la recuperación de la teoría del mito, Schmitt enarbola la idea del mito nacional aun contra el propio Sorel. A partir de la erección del mito de la nación,

\footnotetext{
${ }^{20}$ Para una discusión acerca de las influencias vitalistas en Schmitt, véase Laleff Ilieff (2018)
} 
Carl Schmitt, lector de Georges Sorel.

La crítica al parlamentarismo, el mito de la nación y la «mirada rusa»

Schmitt llevó a término la crítica al parlamentarismo al plantear que la unidad política se halla por fuera del ámbito de la discusión racional, y concomitantemente remarcó el antagonismo con la Revolución Rusa.

En la parte final del artículo intentamos mostrar la perduración implícita de tópicos sorelianos, deteniéndonos en la conferencia «La era de las neutralizaciones y de las despolitizaciones» (1929). Allí vimos que, a pesar de que la figura de Sorel no sea puesta en el centro, la idea de un enfrentamiento vital persiste y se reactualiza, ahora con la evidencia de la necesidad de que haya un conductor en los nuevos márgenes de la politización y en la disponibilidad de la técnica.

En suma, vimos una modulación teórica en el pensamiento de Schmitt desde la crítica al parlamentarismo hasta el reconocimiento del fin de la neutralización. En dicho punto, consideramos que se hizo patente una unificación de la crítica: por un lado, la crítica del parlamentarismo persiste respecto de la situación interna, donde se ve el requerimiento de reencontrar la unidad existencial frente a la disgregación pluralista, por otro lado, se hace necesario lograr una conducción estatal que pueda hacer frente al avanzado «hermano radical». Las consecuencias del carácter total de lo político eran imprevisibles, y sería un Schmitt completamente distinto, luego de la segunda posguerra, quien alertaría con pesimismo acerca de los peligros y desventajas de haber perdido la posibilidad de acotar los conflictos. 


\section{Bibliografía}

Galli, C. (2011). La mirada de Jano. Ensayos sobre Carl Schmitt. (María Julia de Ruschi, Trad.). Buenos Aires: Fondo de Cultura Económica.

Kennedy, E. (2008). Estudio de contextualización. En Los fundamentos históricoespirituales del parlamentarismo en su situación actual (pp. 155-219). Madrid: Tecnos.

Koselleck, R. (1993). Futuro pasado. Para una semántica de los tiempos históricos. (Norberto Smilg, Trad.). Barcelona: Paidós.

Koselleck, R. (2007). Crítica y crisis. Un estudio sobre la patogénesis del mundo burgués. (Rafael de Ludela y Jorge Pérez de Tudela, Trad.) Madrid: Trotta.

Laleff Ilieff, R. J. (2015). Schmitt y la paradoja del Estado total. Discusiones Filosoficas, 16(26), 33-47. https://doi.org/10.17151/difil.2015.16.26.3

Laleff Ilieff, R. J. (2018). El «vitalismo» de Carl Schmitt, entre Hermann Heller y Oswald Spengler. Miríada, 10(14), 149-177.

Meier, H. (2008). Carl Schmitt, Leo Strauss y El concepto de lo político. Sobre un diálogo entre ausentes. (Alejandra Obermeier, Trad.). Buenos Aires: Katz.

Ricci Cernadas, G. (2014). Weimar en crisis: de cara al Estado total. En L. Nosetto (Ed.), Lecturas de Carl Schmitt. Forma y contenido de la teología política (pp. 54-64). Buenos Aires: Instituto de Investigaciones Gino Germani (Universidad de Buenos Aires).

Rossi, L. A. (1999). «El mito más fuerte reposa sobre lo nacional». Carl Schmitt, Georges Sorel y El concepto de lo político. Revista internacional de filosofía política, 14, 147-166.

Schmitt, C. (1968). La dictadura. Desde los comienzos del pensamiento moderno de la soberanía hasta la lucha de clases proletaria. (José Díaz García, Trad.). Madrid: Revista de Occidente.

Schmitt, C. (2001). Teología Política I. Cuatro capítulos sobre la teoría de la soberanía. (Héctor Orestes Aguilar, Trad.). En H. Orestes Aguilar (Ed.), Carl Schmitt, teólogo de la política (pp. 19-62). Ciudad de México: Fondo de Cultura Económica.

Schmitt, C. (2006). La era de las neutralizaciones y despolitizaciones. (Rafael Agapito, Trad.). En El concepto de lo político (pp. 107-122). Madrid: Alianza Editorial.

Schmitt, C. (2008). Los fundamentos histórico-espirituales del parlamentarismo en su situación actual. (Pedro Madrigal, Trad.). Madrid: Tecnos. 
Carl Schmitt, lector de Georges Sorel.

La crítica al parlamentarismo, el mito de la nación y la «mirada rusa»

Schmitt, C. (2009). Catolicismo y forma política. (Carlos Ruiz Miguel, Trad.). Buenos Aires: Areté.

Schmitt, C. (2011). Teoría de la constitución. (Francisco Ayala, Trad.). Madrid: Alianza Editorial.

Schmitt, C. (2012). Sobre los tres modos de pensar la ciencia jurídica. (Montserrat Herrero, Trad.). En Posiciones ante el derecho (pp. 243-315). Madrid: Tecnos.

Schmitt, C. (2014). La oposición entre comunidad y sociedad como ejemplo de una distinción bimembre. Consideraciones sobre la estructura y el destino de tales antítesis. (Alexis Gros, Trad.). Anacronismo e irrupción: Revista de teoría y filosofía política clásica y moderno, 4(7), 171-188.

Sorel, G. (2005). Reflexiones sobre la violencia. (Florentino Trapero, Trad.). Madrid: Alianza Editorial. 